\title{
Native vs exotic: cultural discourses about flora, fauna and belonging in Australia
}

\author{
D. Trigger \& J. Mulcock \\ Anthropology \& Sociology, The University of Western Australia
}

\begin{abstract}
Environmental debates about which plant and animal species 'belong' in particular locations have a growing significance around the world. We argue that ideas about which species constitute weeds or pests and how those species should be managed can be strongly grounded in cultural values and beliefs. Such beliefs are often linked, directly and indirectly, to everyday assumptions about national, regional, local and personal identities. Strong emotional attachments to particular species or landscapes can shape individual and community responses to flora and fauna with implications for issues of sustainable development and planning. This paper focuses on beliefs and practices that are thereby of relevance to urban environmental management. The study setting is the city of Perth, Western Australia. We aim to better understand the connections between nature and culture in a settler-descendant society, focusing on contesting views about 'indigeneity' and 'belonging', in both social and environmental contexts. Sense of place, the notion of a hybrid cultural and environmental heritage, scientifically informed beliefs about environmentally appropriate practices, and contesting aesthetic preferences are key themes in this discussion.

Keywords: cultural landscapes, feelings of attachment, nature and belonging, native and exotic species, culture and identity.
\end{abstract}

\section{Introduction}

Visions of what 'sustainability' entails routinely include social and cultural issues as of critical importance. Both in academic literature (Diesendorf [1], Orr [2]) and applied policy writing (Government of Western Australia [3], Melbourne City Council [4]), social and cultural factors are presented together with economic and ecological topics, as central to the goal of integrated 
prosperity that is sustainable over time. However, discussions of ecological sustainability can also appear unsophisticated in terms of understanding the complexity of socio-cultural factors. At issue in this paper is the increasingly prominent assertion of the importance of 'invasive' species as a significant threat to biodiversity and hence also to ecological sustainability. While there is now a major science-based effort to rid certain environments of what are regarded as 'alien' plants and animals (GISP [5]), how sustainable is this approach in light of social research on a broad range of deeply enculturated attachments to familiar landscapes? Attachments that may be based significantly on sentiments developed during formative life experiences, and which are an assumed part of everyday living, rather than consciously articulated assessments regarding what is good for biodiversity or sustainability.

\section{Sustainability, biodiversity and the lure of 'nativeness'}

In this research, we are interested in how people think and behave in regard to the plants and animals they envisage as part of 'nature', in a society which is debating the place of 'native' versus 'exotic' species. Our case study is Australia, where a quintessentially natural 'wilderness' is commonly located by citizens as far distant from the urban settings of their own lives (Crawford [6], Haynes [7], NSW NPW [8]); yet there is also an emergent interest in 're-naturalising' urban environments in a range of city locations including private home gardens, public parks and remnant patches of bush (Archer and Beale [9]).

We do not dwell here on the various scientific arguments as to why 'native' species of plants and animals are regarded by some experts as the most ecologically sound. This perspective may well be especially significant in Australia, where the boundary of the nation is more or less coterminous with that of a relatively isolated, ecologically distinct continent; as cultural geographers Head and Muir [10] put it, the vegetation that has survived has something of a shared evolutionary history. Indeed, we might say that the relationship between the continent and the nation has facilitated a simplistic distinction between the idea of native species and exotic invasives, these authors noting that this dualism is increasingly evident in public environmental debates and more generally in the national imaginary.

George Seddon [11], among the relatively limited number of scholars who seek to bridge the natural sciences and humanities, comments that to speak of 'Australian plants' may sometimes be useful but it is fraught with difficulties. As he puts it, plants know nothing of nationality. And while the nation is (unusually, in comparison to elsewhere in the world) coterminous with the continent, the Australian land mass encompasses many highly diverse environments, with the plants endemic to one often failing to survive in another. Seddon provides illustrative examples of the lack of fit between flora and Australian national boundaries: northern 'boab' trees also found in Madagascar and southern Africa, figs with nearest relatives in India, and Tasmanian gymnosperms related to species in New Zealand. None of these plants grow everywhere across the Australian continent but do flourish in other countries as well as in particular 
bioregions of Australia. Furthermore, we have the issue of whether recent introductions that have become naturalised in biological terms, should now be regarded as 'Australian plants'.

Seddon's point is that any sharp distinction between 'native' and 'exotic' plants - as with the notion of 'native' animals - at the least requires careful qualification. Does too parochial a view about what 'belongs' in nature contradict the moral importance of openness to the ecological (and cultural) influences of the broader world? Is there a risk of 'wildlife xenophobia'? The kookaburra, for example, a bird indigenous to the east coast of Australia but not the west, was introduced to Western Australia's Swan River coastal plain more than one hundred years ago; in Seddon's [11] view, it is destructive to small bird species, a 'rapacious predator, more disposed to eat the eggs and nestlings of the indigenous birds that have a different evolutionary past and are not adapted to its presence than it is to eat the lizards and snakes of popular illustration'. Yet, apart from this view being contested among scientists, the kookaburra is widely regarded as a national icon, and celebrated as such across many sectors of Australian society (Legge [12]). In 1971, it was officially proclaimed the bird emblem for the State of New South Wales, and the historical reason for its deliberate introduction to Western Australia (and other regions) was that European settlers were so enamoured of its distinctive song [13].

Thus, although there is considerable scientific debate concerning the whole issue of the ecological superiority of native flora and fauna, and furthermore, history teaches us about the risks of extremist eco-nationalism connected with forms of racism (Gould [14]), this matter of which species 'belong' in particular regions is increasingly prevalent. The conflict of values, entailing competing notions of what is appropriate in nature, may occur both among different groups in society (e.g. conservation biologists versus non-experts) and also at times within the consciousness of individuals. In the urban context, it is often the setting of private gardens in which debates rage. Cultural geographer Kay Anderson [15] has pointed out that '[i]t is in the suburban backyard that people, perhaps unwittingly, make their more routine interventions in nature. By clearing ground and arranging space for "gardens", they simultaneously create habitats in which some species of ... animal [and plant] life thrive while others lose out.... [S] uburbs have become ecosystems of their own...'. Our approach is that urban locations potentially reveal much about Australian visions for the construction of landscapes, and simultaneously also much about how cultural identities are conceived. As Tim Flannery [16] observed in his 2002 Australia Day Address: '[n]othing seems to rouse the passions of some Australians so much as disparaging roses, lawns, plane trees and the like'. Flannery proceeded to comment that, "if gardens are a kind of window on the mind, I see in our public spaces a passion for the European environment that indicates we are still, at heart, uncomfortable in our own land'.

In Australia, then, among conservationists, there is increasing publicity given to the importance of ridding the country of 'alien' plants and animals, or at least those which are 'weeds' and 'pests' [17, 18]. Apart from the scientifically credible or contestable justifications for this position, as social scientists we 
focus on the emerging parallel issue of cultural 'belonging', as it may be linked to forms of nature that are embraced or rejected across the citizenry. If, for example, there are similarities of environment in much of Australia and South Africa, such that some plants from both continents do well on both sides of the Indian Ocean, are there socio-cultural reasons as to why the same species is celebrated as an icon in one country yet despised (at least by activist conservationists) in the other setting (Blair [19])? Are there significant culturally formed notions of personal and collective identity - related to nationalism and regions within nation states - that are implicated in the reproduction and change of public opinion concerning which plants and animals belong and the related issues of biodiversity and ecological sustainability? Furthermore, does the debate about ecological belonging carry symbolic significance that overlaps with assumptions about where certain categories of person sit on a moral hierarchy of cultural belonging - whether these persons be descendants of earlier generations of Aboriginal people or historical colonists (or both), more recent migrants, refugees, and so on (Morton and Smith [20])?

\section{What is natural, what is native, what is invasive, what is to be preferred?}

Isis Brook [21] cautions that 'debate around invasive species needs careful handling for both ecological and social reasons'. Like other writers (Comaroff and Comaroff [22], Groening and Wolschke-Bulmahn [23], Helmreich [24]), she notes that 'the rhetoric of invasion and degradation [can] apply both ecologically and culturally', and that 'nativism in ecology' can be uncomfortably linked to racism. In ecological terms, some introduced plants become 'naturalised', that is they can live and reproduce without additional care by a gardener (just as exotic animal species are regarded as 'naturalised' once they survive and reproduce independent of human management). Brook describes those plants which go on to become 'invasive' as the ones that 'spread to ... impact on native flora and fauna'. However, she points out that the flora of Britain is 'a longstanding cosmopolitan blend where notions of pristine nativity are misplaced', and this is a point obviously relevant to much of the world. Nevertheless, in Europe as well as in settler societies like Australia and South Africa, there is concern especially among conservation scientists about an increasing domination of flora by 'the same few "weedy" species' and the associated extinction of 'ousted species'; hence, 'environmental thinking' is that people should either 'not move to environments new to them' or at least 'curb the desire' to make such new places 'feel like home' (Brook [21]).

Here we broach the point that a key driver of people's preferences for plants (and animals) is, indeed, the desire to feel 'at home', often leading appropriately in cultural terms to the introduction of 'plants or forms of gardening that are drawn from somewhere else' (Brook [21]). When we examine 'the affective dimension of flora in human well being', we see that people can 'connect to place through plants', via emotional linkages often forged in childhood or through long association. To illustrate, Isis Brook introspects about her intense 
personal pleasure felt for an unusual small area of verdant lawn when visiting Greece. Aware that Greece is not a place where either the culture or ecology is well suited to this type of 'attachment environment' of her own youth and English background, Brook simply acknowledges that conflicting views between ecological knowledge and emotional desire for certain species and types of gardens, can coexist within individuals. She goes on to report a North American study (Worthen [25]) of planting choices which shows that people commonly desire 'plants that make them feel at home regardless of what is appropriate for the climate or ecologically sound', and that on retirement older citizens feel drawn back towards the vegetation characteristic of their youth. This type of emotional connection to what we might term the 'primal landscape' of youth is currently of some interest in social science and humanities writing (Milton [26], Measham [27], Gayton [28]).

When we turn to the Australian material, the matter of primal landscapes or attachment environments that are experienced during people's formative years, are germane to a widespread assumption that citizens share a mixed ecological heritage. Despite the impassioned science talk of replacing 'exotic' plants and animals with 'natives', things that belong both ecologically and culturally (Archer and Beale [9], Low [29]), most Australians have grown up with environmental hybridity and regard it as the norm. To illustrate, we can note recent nationwide survey data indicating that pet ownership (especially of introduced cats and dogs) remains common across the majority of households, with four out of five Australians reporting such family pets during childhood (McHarg et al. [30]). And of the some 27,000 'alien' plants that have been introduced to Australia over the past 200 years, the domestic garden industry has been the major importer, and many plants regarded as invasively destructive in scientific terms remain for sale and subject to very considerable consumer demand (Groves et al. [31]). A leading Australian garden writer comments that 'blending natives with exotics' creates 'new and exciting gardens with style and an authentic Australian ambience even though the plants used may be from many lands' (Urquhart [32]). Popular garden magazines [33], and even official government publications promoting water conservation [34], list many exotic species (alongside natives) as 'drought-resistant' and 'water wise'. Yet the lure of nativeness, via attributing this quality to what is asserted to be most 'natural', remains significant in conservationist discourse. And just how Australians negotiate between inherited (and desired) hybrid landscapes, on the one hand, and the implied ecological and associated moral superiority of native species, on the other, is the focus of our empirical inquiries.

\section{Nature, culture and belonging in an Australian city: the case of Perth, Western Australia}

The data obtained so far arise from our approach as qualitative ethnographers. The material includes: pilot inquiries with 36 university students; 30 extended ethnographic interviews, conducted mostly with people who have a strong interest in native plants and/or animals; 38 short interviews with individuals 
attending a native plant sale; a selection of written comments from 309 Perth people responding via self-selection to a nation wide online survey seeking attitudes to urban wildlife (ABC Radio [35]); and assorted media and documentary reports. We present illustrative findings under two headings.

\subsection{Science versus landscapes of attachment}

In reviewing a campaign to eradicate an introduced species of duck in Britain, anthropologist Kay Milton [36] reflects on the extent to which the desire to preserve maximum biological diversity 'makes sense outside science'. She discusses how eliminating an introduced species, in order to preserve the purity of a species regarded as native, will not necessarily make sense to many ordinary citizens. Our data from Perth pose the same question, in that a perspective emphasising ecological sustainability as incompatible with exotic species, can clearly conflict in the urban environment with highly valued and familiar senses of place. A striking case is the tension between 're-naturalising' what might be termed 'European-style' parks in inner city areas and maintaining introduced flora as part of a valued non-native heritage. 'The park's heritage is not native and it will be protected', said the mayor of one Council recently, in response to an expert report recommending the removal of deciduous vegetation such as 'plane trees' which were introduced historically from Britain. The latter view seeks, from a conservationist perspective, to 'restore things that have been either totally destroyed or half wrecked by progress', as explained by a Councillor we interviewed. This commitment to 're-naturalising' the urban habitat is connected with a high valuation of the historical presence of 'Indigenous' (i.e. Aboriginal) people. However, those opposed speak with pride of such environments that were constructed in 'a European style', and of how they need more plantings of introduced trees, 'to maintain the park's character' (Voice News [37]).

To further illustrate such tensions, between the language of science and broader public sentiments, we have the fascinating case of rainbow lorikeets. This bird was introduced to Perth during the early 1960s and is native to eastern Australia where it is valued highly. In Perth, a population of more than 10,000 is now said to enjoy communal roosting sites, especially amidst 'exotic' eucalypts, introduced palms and extensive fruit orchards, but also in native vegetation. The official view is that the bird competes with several locally indigenous species and that it is a 'pest' in regard to agriculture. Rainbow lorikeets can be shot or live-trapped legally outside the city though (probably for safety reasons) this does not apply in the metropolitan area (Lamont [38]). Such gardening enthusiasts as the following writer also embrace this scientific view: 'rainbow lorikeets ... are stealing the habitats of local species' and their presence is encouraged by planting 'eastern states' flora (Passmore [39]). And among Perth contributors to the $\mathrm{ABC}$ radio survey, we find rainbow lorikeets described as: 'feral birds that will bully and drive away' native birds; 'horrid, ugly, noisy pests [that] destroy everything as they invade and take over'; and birds with 'loud raucous calls [that] are not typical of our Western Australian birds and can be unnaturally loud' [our emphasis]. 'Though beautiful, they do not belong here', said one contributor. 
However, attachments to this species arising from familiarity and its aesthetic beauty are expressed with equal passion. A young couple interviewed, who had a pet lorikeet (purchased from a shop) which had been hand-raised from 9 weeks of age, described the experience as 'just like having a baby'. The bird was like a 'kind of a child' and 'definitely part of the family'. They believe the bird calls them 'mummy' and 'daddy' and they love it dearly. When we asked what they thought about the ecological argument that wild rainbow lorikeets did not belong in Perth, the response was much more generous than the scientific concern with the bird as a feral 'pest'. While acknowledging it was apparently an introduced species, the couple felt the bird should now be accepted as a delightful part of the city's fauna.

In the context of such strong emotions articulated in relation to both introduced and native species, cats are the urban animal about which there are probably the most divisive views. While some non-owners are unwilling to concede that cats have any place in Australia at all ('the only good cat is a dead one', as one contributor to the ABC survey put it), the parallel opposite view is the groundless justificatory presumption among some cat owners that their loved pets are more likely to kill birds that are introduced rather than native. This suggestion embraces the idea of native birds as morally more valuable, while nevertheless passionately supporting the non-native cat. Such a blurring of any consistent values attributed to 'native' and 'exotic' species is common across our data. For example, those expressing positive sentiments about native animals, can report how non-native food plants are appropriately consumed in domestic gardens - thus, native possums and kangaroos eat exotic roses, native parrots like introduced pomegranates and other fruit trees, native insectivorous birds are attracted to the open ground of vegetable patches, native ibis and wagtail birds find introduced grass lawns conducive to their needs, and native frogs like lemon scented gums that do not belong to southwest Australia in ecological terms.

\subsection{Flora, fauna and the formation of socio-cultural identities}

In the light of this mix of views about native and non-native nature, our inquiries have prompted some richly evocative data when people are asked about their senses of identity in relation to feelings for particular landscapes. Examples include a woman interviewee from a farming background who travelled for nine years in Europe; she reports how she 'fell in love with beautiful gardens, the colour, and how they were created', and how she feels 'very linked to my ancestry and my ancestry is English and when I go to England and I look at the types of gardens there and the greenery, I feel a very deep pull to that, a very primal pull'.

When we probed for whether a choice to plant native or exotic plants may be connected to a sense of national belonging or 'feeling Australian', the responses were mixed, but instructive. Some identified with Aboriginal landed identities: 'I have a connection with the land like the original inhabitants did, so I want to recreate that around my house', commented a male speaker aged in his 50s. Others were keenly aware of their struggle to feel 'at home': 'As a Caucasian ... I feel I am an introduced species myself, and I especially like bush land because 
it gives me a sense of something that was there before I came, before my ancestors came ... perhaps it is a kind of guilt because my ancestors came uninvited but I think I'm trying to reconnect, trying to say look, I don't want to do you harm, I want to justify my presence here by trying to re-establish something which people like me have spoiled, like a restitution' (female speaker aged 35 years).

Yet such a view seems not inconsistent with an overall commitment to ecological hybridity, a form of consciousness appropriately characterised as postcolonial, i.e. arising from recognition of the entrenched cultural hybridity that constitutes the modern Australian nation. Thus, our informants comment: 'there's this long thing going backwards to where we came from and I'm really aware ... that I like an environment ... where I see a mixture ... of pasture and bush ... I do think we're transplants here, but we also belong now, so it's interesting'; 'I love the native plants, ... but if I were restricted to the native plants I would feel somewhat impoverished'; 'a lot of things that people call weeds I love, like morning glory'; 'I do think now that both indigenous plants and exotic plants belong within the urban environment here and I think that it's much more beautiful because it's got a mixture'.

In the city of Perth, then, it is a mix of nativeness and introduced forms that appears most generally accepted. And in all of this the links between sentiments about what belongs in nature and what belongs in society are evident. We finish with a quote from a woman which, while certainly not indicative of all citizens' views, puts this issue well. Referring to her 'epiphany', following learning about some native plant uses from an Aboriginal tour guide, she comments: 'it just hit me like a ton of bricks and I started crying, ... I didn't know anything about these plants, I didn't know what they were called, I didn't know what you would use them for and I suddenly realised how odd it was to feel like a total alien in ... the land that you were born into'.

\section{Conclusion}

In the context of an Australian city, we have described a mix of overlapping and contesting views about what 'belongs' in nature. We have sought to describe the character of contesting sentiments (not always articulated consciously) in regard to native versus introduced flora and fauna. While the ecological significance of local biodiversity is taken for granted in scientific perspectives on sustainability, the implications of this qualitative social research are that attempts to change behaviour and/or thinking among city residents will require engagement with an ambivalent mix of assumptions and beliefs - assumptions and beliefs that are seemingly informed by general notions of what 'belongs' in a settler-descendant society. This is to raise the issue of links between what citizens believe belongs in nature and what they understand to be the constituents of their cultural identities. To this extent, knowledge of ecological issues is unlikely to be the sole driver of people's preferences for plants, animals and the general character of urban landscapes. Of critical relevance will also be people's senses of what is appropriate in terms of their formative life experiences, their consequent familiarity with particular natural and cultural landscapes, and their senses of 
what forms of nature are commensurate with notions of Australian national and regional identities.

\section{References}

[1] Diesendorf, M. Principles of ecological sustainability (Chapter 3). Human ecology, human economy, eds. M. Diesendorf \& C. Hamilton, Allen \& Unwin: St Leonards, pp. 64-97, 1997.

[2] Orr, D. Four challenges of sustainability. Conservation biology, 16(6), pp. 1457-60, 2002. doi: 10.1046/j.1523-1739.2002.01668.x

[3] Government of Western Australia, Hope for the future: the Western Australian State sustainability strategy, Sustainability Policy Unit, Government of Western Australia: Perth, pp. 4-7, 20-24, 2003.

[4] City of Melbourne, Growing green: environmental sustainability plan for the city of Melbourne's open space and recreational facilities (final report), Melbourne City Council: Melbourne, pp. 9-10, 2003.

[5] GISP (Global Invasive Species Programme), www.gisp.org/.

[6] Crawford, J. Community attitudes to wilderness-based recreation on the Great Barrier Reef. Reef research, 8(1), pp. 1-4, 1998.

[7] Haynes, R., From habitat to wilderness (Chapter 3). Disputed territories: land, place \& culture in settler societies, eds., D. Trigger \& G. Griffiths, Hong Kong University Press: Hong Kong, pp. 81-107, 2003.

[8] NSW National Parks \& Wildlife, Urban wildlife renewal: growing conservation in urban communities, Report by Woolcott Research, 2002. www.nationalparks.nsw.gov.au/npws.nsf/Content

Urban+wildlife+research

[9] Archer, M. \& Beal, B. Going native: living in the Australian environment, Hodder: Sydney, pp. 306-38, 2004.

[10] Head, L. \& Muir, P., Nativeness, invasiveness and nation in Australian plants. The Geographical Review, pp. 6-7, in press.

[11] Seddon, G., Prologue. The Australian garden, ed. D. Snape, Bloomings Books: Melbourne, pp. 8-19, 12, 2002.

[12] Legge, S. Kookaburra: king of the bush, CSIRO publishing: Collingwood, pp. 1-14, 113, 2004.

[13] Australian emblems. http://mzsrv.zoo.org.au/emblems/nswbird.htm

[14] Gould, S. J., An evolutionary perspective on strengths, fallacies and confusions in the concept of native plants. Nature \& ideology: natural garden design in the twentieth century, ed. J. Wolschke-Bulmahn, Dumbarton Oaks Research library \& collection: Washington DC, pp. 11-19, 1997.

[15] Anderson, K., Culture and nature at the Adelaide Zoo. Transactions of the Institute of British Geographers NS, 20, p. 275, 1995.

[16] Flannery, T., The day, the land, the people. The Australia Day Committee, www.adc.nsw.gov.au/tim_welcome.html.

[17] Agriculture \& resource management council of Australia and New Zealand, The national weeds strategy: a strategic approach to weed problems of national significance, Commonwealth of Australia: Canberra, 1997. 
[18] Cooperative Research Centre of biological control of pest animals. www.pestanimal.crc.org.au

[19] Blair, J., Battling Australian icons in South Africa. Eco Voice: Australia's Environment Newspaper, 8, p. 4, 2005.

[20] Morton, J. \& Smith, N., Planting indigenous species: a subversion of Australian eco-nationalism. Quicksands: foundational histories in Australia and Aeoteroa New Zealand, eds., K. Nueman, N. Thomas and H. Ericksen, University of New South Wales Press: Sydney, pp. 153-75, 1999.

[21] Brook, I., Making here like there: place attachment, displacement and the urge to garden. Ethics, place \& environment, 6(3), pp. 227-34, 2003.

[22] Comaroff, J. \& Commaroff, J. Naturing the nation: aliens, apocalypse, \& the postcologial state. HAGAR: International social science review, 1(1), pp. 7-40, 2000.

[23] Groening, G. \& J. Wolschke-Bulmahn, Some notes on the mania for native plants in Germany. Landscape journal, 2, pp. 116-26, 1992.

[24] Helmreich, S. How scientists think: about 'natives', for example. Journal of the Royal Anthropological Institute, 11, pp. 107-28, 2005.

[25] Worthen, H. Signs of life, MLA thesis, U of California: Berkeley, 1975.

[26] Milton, K. Loving nature: towards an ecology of emotion, Routledge: London \& New York, pp. 62-64, 2002.

[27] Measham, T. Learning about environments: the significance of 'primal landscapes', unpublished paper given at University of Wollongong, 31.3.2005.

[28] Gayton, D. Landscapes of the interior: re-explorations of nature \& the human spirit, New Society: Gabriola Island, Canada, pp. 71-77, 1996.

[29] Low, T. Feral future: the untold story of Australia's exotic invaders, Penguin: Ringwood, Australia, 2001.

[30] McHarg, M, C. Baldock, B. Headey, Alec Robinson, National people and pets survey, Report to Urban Animal Management Coalition 1995. www.petnet.com/au/People_and_Pets/52UAMR.html

[31] Groves, R., R. Boden \& W. Lonsdale, Jumping the garden fence: invasive garden plants in Australia and their environmental and agricultural impacts, CSIRO report for WWF-Australia, WWF-Australia, Sydney, pp. 7-9, 2005.

[32] Urquhart, P., The new native garden, New Holland: Sydney, p. 7, 2002

[33] West Australian Gardener, pp.8-9, Summer 2003.

[34] Selecting water wise gardens, leaflets, Water Corp. of Western Australia.

[35] ABC Radio, Wildwatch2: quest for pests. http://abc.net.au/wildwatch/

[36] Milton, K. Ducks out of water: nature conservation as boundary maintenance (Chapter 11). Natural enemies: people-wildlife conflicts in anthropological perspective, Routledge: London \& New York, p.236, 2000.

[37] Voice News newspaper, 23-30.4.2005

[38] Lamont, D., Farmnote No.8: Rainbow Lorikeet, Western Australia Departments of Agriculture \& Conservation and Land Management, 2002.

[39] Passmore, N., Keep the locals happy. Sunday Times newspaper, 24.9.2003. 